\title{
Investigating the Relationship between Psychological Empowerment of Nurses and Organizational Learning in Iran: A Study on Tabriz Imam Reza Hospital
}

\author{
Mohammadakbar Sheikhzadeh ${ }^{1}$ \\ Habibollah Salarzehi2, ${ }^{*}$ \\ Rasoul Yavari ${ }^{3}$

\begin{abstract}
${ }^{1}$ Department of Information technology, Higher Educational Complex of Saravan, Iran ${ }^{2}$ Associate professor of management, University of Sistan and Baluchestan, Iran, Corresponding Author 3MA in governmental management, University of Sistan and Baluchestan, Iran
\end{abstract}

\author{
Doi:10.5901/mjss.2016.v7n5p371
}

\begin{abstract}
Today organizations work permanently in unsustainable environments and need to frequent changes and learning in individual, group, organizational, and inter-organizational levels. The aim of this study is to investigate the relationship between organizational learning and psychological empowerment in one of Tabriz hospital. Statistical population of this research is employed nurses in various work shifts that 207 ones were selected by simple random method as statistical method and personal information questionnaire, Marsick Watkins organizational learning questionnaire (2003), and Spritzer psychological empowerment questionnaire (1995) were used to collect data. Cronbach's alpha coefficient was used in order to determine questionnaires reliability coefficient Pearson correlation coefficient and linear regression, functional analysis, and structural analysis were used to analyze data. Correlation coefficient results showed that there is positive and significant relationship with $99 \%$ confidence level between organizational learning and psychological empowerment aspects. In addition, regression results showed that predictor variables (organizational learning, team learning, and personal learning) explain $53.8 \%$ of variance (changes) of psychological empowerment variable significantly. Conclusion: organizations should enhance all aspects of psychological empowerment for maturity and it will be possible when we significantly focus on organizational learning.
\end{abstract}

Keywords: organizational learning, team learning, personal learning, psychological empowerment

\section{Introduction}

Analysis of organizational learning has been studied incrementally in recent years. Some studies have focused on psychological approach, sociological approach or are built on organizational theory view. Recently, learning has been considered as an infrastructural competitive advantage according to strategic view as heterogeneous source in organizations. Although, studies in organizational learning field provide some related visions, there are some aspects that are not analyzed yet. On the other hand, this idea is accepted that organizational learning is the main elements of success in global competitive markets (Jerez Gomez, 2005). Therefore, according to Bontis, Kroos and Halland" (2002) and "Nonaka and Takeuchi" (1995), learning ability can be organizational innovation and protecting competitive advantage in chaos organization. Learning promotes innovative activities and quality as the main determiners of success in competitive environments. Consequently, a company can protect one competitive advantage by producing a product or quality management permanently. Culture of promoting organizational learning improves individual, group, and organizational learning and will be a modification message for organizational learning. In addition, it improves organizational abilities to learn innovative, efficient, effective activities and increase capacities. "Rusermale and Didis, (2004) showed that promoting learning by foreigner partners has positive effect on products development and modern and innovative services. According to report of "Baker and Sinkula" (1999) report, organizations by learning orientation can investigate foreign environment for paradigm of new technology leading to innovation (Hung et al., 2011)

One of the main features of new organization is their forming based on learning; therefore, managers and employees are always learning and getting new skills, because power of each organization is related to permanent learning of managers and employees (Eslamiyeh, 2009). Organization learning is a process entered by three individual, group, and organizational aspects into organization and information is distributed and interpreted and organization continues living. This process influence on employees in work space. This matter moves researcher toward 
organizational learning and investigation its effects on empowerment as a factor expected to greatly influence on human force empowerment in an organization.

Efficient and effective human force is the main index of an organization priority than other organizations (Esmaeili, 2002). So empowered forces in each organization can increase organizational performance, psychological vitality of employees, better expression of organizational eminent purposes and also accessibility to individual, group, and organizational purposes besides reducing delay, absence, and motivation.

In health organization, attention to work force is doubly important. Actually, health of active and efficient forces is ensured in other organizations by health organizations attempts. Therefore, making satisfaction in inter-organizational forces makes satisfaction inn total organization that leads to easy accessibility to organization purposes it means promoting society health. An important part of human force of organizations is constituted by nurses; however, they are unfortunately neglected and put away in rival era and they mostly have sense of weaknesses in their workplace. (Haug and Laaschinger 1996).) Therefore, it is tired in this research besides explaining the mentioned notions to introduce ideal abilities of nurses in all organizations particularly in Imam Reza Hospital of Tabriz as the first step.

\section{Material and Methods}

The present research is applied, because it is used by purpose of using findings results from solutions of organizations and descriptive according to method, because it states issue and describes it by collecting data and how the present research is because it evaluates the relationships among organizational learning and nurses psychological empowerment. It is surveying, because it used questionnaire and interview nurses ideas and cross-sectional, because its related data was collected once with less than 3 month interval.

\section{Sampling}

Statistical population in this research according to research variables means organizational learning and psychological empowerment is nurses in Imam Reza Hospital of Tabriz city. Number of statistical population is 450 people (400 women and 50 men). They were selected by Krejcie and Morgan (1970), Cohen (1969) and using simple random sampling with volume of 207 samples, so 207 questionnaires were filled and collected.

\section{Survey Instrument}

According to research purpose, questionnaire was used to collect data. Among the present questionnaires about research, Watkins organizational learning questionnaire and Marsick (2003) and Spritzer psychological empowerment questionnaire (1995) were used. Organizational learning (personal, group, organizational level) and psychological empowerment (significance, self-determination, effect, and confidence) were investigated and tested among nurses of Imam Reza Hospital of Tabriz city. Content validity method was used to test questionnaire validity. In this regard, professors ideas were asked, then vague questions were generally revised. Finally, final questionnaire was formulated by new edition and changes in questions conceptions. Cronbach alpha coefficient was used by SPSS software to measure reliability that this coefficient is known as one of reliable coefficient and it is between 0 and 1 . Reliability coefficient of 0 shows non-reliability and reliability coefficient 1 shows full reliability that 0.915 was obtained in this research that is higher than 0.7 and showed questionnaire has enough reliability and statistical methods such as Spearman correlation, regression test, and also functional and structural analysis method were used to analyze data.

\section{Results}

$\mathrm{H}_{0}$ : there isn't positive and significant relationship between aspects of organizational learning and psychological empowerment and its aspects.

$\mathrm{H}_{1}$ : there isn't positive and significant relationship between organizational learning aspects and psychological empowerment and its aspects.

In order to test $\mathrm{H}_{1}$, first Pearson correlation test and linear regression were used. Table (1) shows Pearson correlation among variables of this research means organizational learning, its aspects, and psychological empowerment. As it is seen, organizational learning and its aspects have positive and significant relationship with psychological empowerment and and its aspects. 
Table (1): Pearson correlation coefficient among organizational learning and its aspects with psychological empowerment $(n=207)$

\begin{tabular}{|c|c|c|c|c|c|}
\hline Variable & & $\begin{array}{l}\text { Organizational } \\
\text { learning aspect }\end{array}$ & $\begin{array}{l}\text { Team learning } \\
\text { aspect }\end{array}$ & $\begin{array}{c}\text { Personal learning } \\
\text { aspect }\end{array}$ & $\begin{array}{l}\text { Total organizational } \\
\text { learning }\end{array}$ \\
\hline \multirow[t]{2}{*}{ Psychological empowerment } & Correlation & $0.556^{\star \star}$ & $0.480^{* \star}$ & $0.520^{\star *}$ & $0.575^{\star \star}$ \\
\hline & Significance & 0.000 & 0.001 & 0.000 & 0.000 \\
\hline \multirow[t]{2}{*}{ Significance } & Correlation & $0.315^{*}$ & 0.203 & $0.326^{*}$ & $0.407^{*}$ \\
\hline & Significance & 0.042 & 0.148 & 0.022 & 0.010 \\
\hline \multirow[t]{2}{*}{ Competence } & Correlation & $0.642^{\star \star}$ & $0.587^{* \star}$ & $0.495^{\star \star}$ & $0.686^{* \star}$ \\
\hline & Significance & 0.000 & 0.000 & 0.002 & 0.000 \\
\hline \multirow[t]{2}{*}{ Self-determination } & Correlation & $0.472^{\star \star}$ & $0.304^{*}$ & 0.180 & $0.438^{* *}$ \\
\hline & Significance & 0.003 & 0.035 & 0.237 & 0.009 \\
\hline \multirow[t]{2}{*}{ effect } & Correlation & $0.787^{\star \star}$ & $0.621^{\star \star}$ & 0.539 ** & $0.796^{\star \star}$ \\
\hline & Significance & 0.000 & 0.000 & 0.000 & 0.000 \\
\hline \multirow[t]{2}{*}{ confidence } & Correlation & $0.464^{\star \star}$ & $0.458^{*}$ & 0.271 & $0.482^{\star \star}$ \\
\hline & Significance & 0.002 & 0.001 & 0.057 & 0.002 \\
\hline
\end{tabular}

** Correlation is significant at the 0.01 level (2-tailed).

Table (2): Regression model summary of organizational earning and psychological empowerment $(n=207)$

\begin{tabular}{|c|c|c|c|}
\hline R & R Square & Adjusted R Square & Std. Error of the Estimate \\
\hline $0.681^{\mathrm{a}}$ & 0.538 & 0.278 & 6.016 \\
\hline
\end{tabular}

Predictors: (Constant), personal learning, organizational learning, team learning

As it is seen, predictor variables (organizational learning, team learning, and personal learning) are significant that organizational learning explains $53.8 \%$ of variance (changes) of psychological variable. In addition, data of table (3) show predictor variables regression analysis means organizational learning and its aspects. As it is seen, since beta of all variables is positive, it can be claimed that increase and decrease of organizational learning can increase or decrease dependent variable (psychological empowerment) and direct effect of independent variable is explicit on dependent variable.

Table (3): regression analysis to predict organizational learning and its aspects on psychological empowerment $(n=207)$

\begin{tabular}{|l|c|c|c|c|c|}
\hline Predictor variables & B & Std, Error & Beta & T & Sig. \\
\hline Constant & 24.492 & 5.780 & & 5.208 & 0.000 \\
\hline Organizational learning aspect & 0.773 & 0.196 & 0.556 & 3.952 & 0.000 \\
\hline Team leering aspect & 0.039 & 0.355 & 0.027 & 0.111 & 0.912 \\
\hline Personal learning aspect & 0.536 & 0.501 & 0.238 & 1.069 & 0.293 \\
\hline
\end{tabular}

As it is seen, organizational learning is the first input variable in regression formula, because it has the highest beta than other constituting elements of organizational learning. (Beta=0.556) in the second and third elements means team and personal learning has more than 0.05 significance level, then they don't inter to regression equation. Then regression formula for psychological empowerment of dependent variable is as following:

Psychological empowerment $=(0.556)$ organizational learning

Since all items of table (3) are positive, and results of other tables have less than 0.05 significance level, it can be claimed that there is significant relationship between organizational learning and psychological empowerment. 


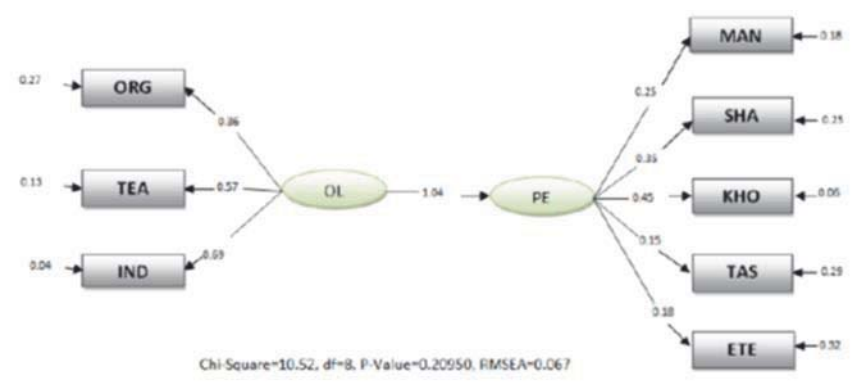

Diagram (1): Organizational learning standard SEM and psychological empowerment

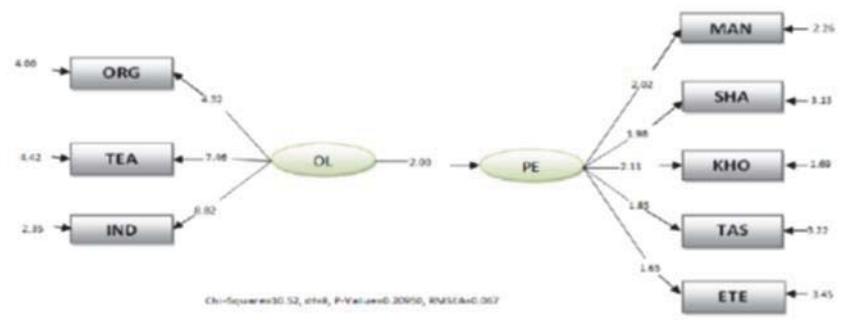

Diagram (2): Significance coefficient between organizational learning and psychological empowerment

Since Byrne (1998), in obtained results from structural equation analysis Chi-2 ratio on freedom degree should be less than 3 to have proper fitness. In addition, RMSEA should be less than 0.08 and RMR less than 0.045 and values of GFI ، IFI ‘CFI ‘NNFI ‘NFI ‘AGFI are more than $90 \%$ to have very good fitness and it is acceptable for more than $85 \%$ fitness. In this model, abbreviation words were used for more simplicity to draw diagrams that are seen in table (1) and (2).

Table (4): Summary of SEM model fitness

\begin{tabular}{|c|c|c|c|c|c|c|c|c|c|}
\hline Chi-square & df & RMSEA & GFI & AGFI & NFI & NNFI & CFI & IFI & RMR \\
\hline 10.52 & 8 & 0.067 & 0.94 & 0.92 & 0.96 & 0.98 & 0.97 & 0.98 & 0.041 \\
\hline
\end{tabular}

As it is seen, for chi-2 being less than freedom degree and RMSEA less than 0.08, and other cases according to Byrne (1998) model re significant according to values in diagrams (1) and (2) and table (4) and model has proper fitness.

\section{Discussion}

This research investigates the relationship between organizational learning and nurses' psychological empowerment in Imam Reza Hospital in Tabriz city who work in 2 various shifts. According to obtained data and analysis, results of this research on 207 nurses, (180 women and 27 men), showed the significant relationship between organizational learning aspects and psychological empowerment of nurses in Imam Reza Hospital in Tabriz in 95\% significance level. In addition, there is positive and direct correlation between 2 variables and their aspects.

Results of hypotheses showed the significant relationship between organizational learning and psychological empowerment. Results of hypotheses (table (1)) according to research of "Ganji" (2010) that investigated the relationship between organizational learning and psychological empowerment in industrial town of Lorestan province are in agreement with result of direct relationship among organizational learning and psychological empowerment that was accepted after hypothesis analysis. In addition, findings of this research with results of "Dastgardi" (2008) showed that there is positive and strong relationship between organizational learning and psychological empowerment. There is positive and very strong relationship between organizational learning and psychological empowerment. There is very strong and positive relationship between organizational learning of employees and self-determination. There is very 
strong and positive relationship between organizational learning of employees and sense of effective. There is very strong and positive relationship between organizational learning of employees and sense of confidence. There is very strong and positive relationship between organizational learning of employees and psychological empowerment. According to results of the second question (table (2)), it can be concluded that importance of predictor variables means (organizational learning, team learning, personal learning) is $53.8 \%$ of psychological empowerment variable variance. According to table (3), it can be stated that organizational learning aspect is important for nurses more than personal and team learning. In addition, according to obtained results from functional analysis and path diagram, it can be concluded that used model in this research has proper fitness and is acceptable. It means managers should have more attention to organizational learning in organizations, because "Stata" (1989) knows innovation as result of personal and organizational learning and also as the only sustainable competitive advantage in industry. Moreover, results of this research are in agreements with the ones from research of Jimenez and Valle (2011), Liao and others (2008), Coreyargon (2007), Holt and others (2002), Mishra and Basker (2010) and Chang and Leo (2008).

\section{Conclusion}

All organizations including all public and private ones need to increase their organizational learning, because its higher level increases employees' empowerment level. Consequently, it is suggested that present organization or other organizations should invest on organizational learning to get to their employee' empowerment.

\section{References}

Hancer, Murat; George,Thomase,(2003), Psychological empowerment of non-supervisory employees working in full-service restaurant; International Journal of Hospitality Management, 22 : 3-16.

Haug E. B and Laaschinger H. K. S.(1996).Power and opportunity in public health nursing work environment, public health nursing, 12 (1):42-9.

Herndon, Craig.(2006). Peer Review and Organizational Learning: Improving the Assessment of Student Learning, Research \& Practice in Assessment Volume1,Issue1.

Hochwalder, Jacek and Brucefors, Agneta Bergsten.(2005). Psychological empowerment at the workplace as a predictor of ill health, Personality and Individual Differences 39, 1237-1248.

Hult, G. Tomas M. Ferrell, O.C. and Hurley, Robert F.(2002). Global organizational learning effects on cycle time performance, Journal of Business Research 55,377-387.

Hung, Richard Yu Yuan. Lien, Bella Ya-Hui. Yang, Baiyin. Wu, Chi-Min and Kuo, Yu-Ming.(2011). Impact of TQM and organizational learning on innovation performance in the high-tech industry, International Business Review $20,213-225$.

Jerez-Gomez, Pilar. Cespedes-Lorente, Jose and Valle-Cabrera, Ramon.(2005). Organizational learning capability: a proposal of measurement, Journal of Business Research $58,715-725$.

Jimenez- Jimenez, Daniel and Sanz-Valle, Raquel.(2010). Innovation, Organizational Learning, and performance, Journal of Business Research64,408-417.

Liao, Shu-hsien. Fei, Wu-Chen and Liu, Chih-Tang.(2008). Relationships between knowledge inertia, organizational learning and organization innovation, Technovation 28, 183-195.

Mishra, Bijaya and Bhaskar, A.Uday.(2010). Empowerment: a necessary attribute of a learning organization, Organizations and Markets in Emerging Economies, Vol. 1, No. 2(2).

Aragon-correa,j. Alberto;Garcia-Morales,Victor J.;Cordon-Poza, Eulogio,(2007), Leadership and organizational learning's role on innovation and performance: Lessons from Spain, Industrial Marketing Management 36: 349 - 359.

Oladipo, S.E. (2009). Psychological Empowerment and Development, Edo Journal of Counselling, Vol. 2, No. 1.

Safari, Khalil. Rastegar, Rastegar and Jahromi, Reza Ghorban.(2010). The relationship between psychological empowerment and entrepreneurship among clerks of Fars Payame Noor University, Procedia Social and Behavioral Sciences 5, 798-802.

Sense, Andrew J, (2011), the project workplace for organizational learning development, International Journal of Project Management $x x: 1-8$.

Spector, J. Michael and Davidsen, Pal I. (2006). How can organizational learning be modeled and measured? Evaluation and Program Planning 29, 63-69.

Suominen, H.,Leino-Kilpi,H;Merja,M.;Irvine Doran,D.;Puukka,P.,(2001), Staff empowerment in Finnish intensive care units, Intensive and Critical Care Nursing 17, 341-34.

Wahlin,Ingrid ;EK,Anna-Christina;Idvall,Ewa,(2010), Staff empowerment in intensive care: Nurses' and physicians' lived experiences; journal homepage: www.elsevier.com/iccn.

Wahlstrom, Bjorn. (2011). Organizational learning - Reflections from the nuclear industry, Safety Science 49, 65-74.

Barrette, lacques. Lemyre, Louise. Corneil, Wayne and Beauregard, Nancy.(2007). Organizational learning among senior public-service executives: An empirical investigation of culture, decisional latitude, and supportive communication, Canadian Public Administration / Administration Publiquedu Canada Volume 50, NO. 3, PP.333-353. 
Barton, Harry and Barton, Lisa C.(2011). Trust and psychological empowerment in the Russian work context, Human Resource Management Review $21,201-208$

Cegarra-Navarr, Juan Gabriel. Jimenez, Daniel Jimenez and Martınez-Conesa, Eusebio Angel.(2007). Implementing e-business through organizational learning:

Chang,Li-Chun ; Liu,Chieh-Hsing,(2008), Employee empowerment, innovative behavior and job productivity of public health nurses: A cross-sectional questionnaire survey, International Journal of Nursing Studies 45 : 1442-1448.

Dimovski, Vlado. Skerlavaj, Miha. Kimman, Mok and Hernaus, Tomislav.(2008). Comparative analysis of the organizational learning process in Slovenia, Croatia, and Malaysia, Expert Systems with Applications 34 , 3063-3070.

Esmaeili, k.(2002). Organizational commitment, Management journal, (77-8):246.

Fook, Chan Yuen. Brinten, Linton. Sidhu, Gurnam Kaur and Fooi, Foo Say.(2011). Relationships between Psychological Empowerment with Work Motivation and Withdrawal Intention among Secondary School Principals in Malaysia, Procedia Social and Behavioral Sciences $15,2907-2911$.

Greijn, Heinz.(2008). Organization learning, A gateway for capacity development Capacity. Issue33.

Abili, Khodayar and Naseti Zaei, Naser (2009). The relationship between psychological empowerment and organizational commitment of nursing personnel in Zahedan, Yazd Health Research Quarterly Issue, No. first and second

Beyginia, Abdorreza, Sardari, ahmad Mousavi, Majid and Kiyani Bakhtiyari, Abolfazl (2009) The effect of cognitive empowering employees on the factors affecting the productivity of human resources, Fifth Conference on Human Resource Development.

Dastgardi, Kazem (2008) The relationship between empowerment and organizational learning physical education, thesis Tehran University, Faculty of Physical Education and Sport Sciences.

Ganji, Akram (2010) the relationship between organizational learning and organizational performance industrial firms of the province, the first international conference and innovation management.

Islamiyeh, Fatemeh (2009). Learning Organizations, Department of Education, Mahan (management information), http://mahanco.com/ component/content/article/39.

Sharifi, ASghar, Ismaeilieh, Fatemeh (2008). The relationship between organizational learning and the use of information and communication technologies Islamic Azad University, Garmsar branch New Approaches Journal of Educational Management, first year, second edition. 